\title{
Design and Simulation of Improved Soft Computing Based MPPT for Solar PV System Under Variable Irradiance Condition
}

\author{
Surendra Singh Dua ${ }^{1}$, Dr. Ruchi Sharma ${ }^{2}$ \\ ${ }^{1} \mathrm{PhD}$ Scholar, Department of Electronics and Communication Engineering,, Vivekananda Global \\ University, Jaipur, Rajasthan, India \\ ${ }^{2}$ Professor, Department of Electronics and Communication Engineering,, Vivekananda Global \\ University, Jaipur, Rajasthan, India
}

Article History: Received: 10 November 2020; Revised 12 January 2021 Accepted: 27 January 2021; Published online: 5 April 2021

\begin{abstract}
Renewable energy sources are becoming more common in the energy generation field these days. Renewable energy sources such as photovoltaic (PV) systems, wind power (WP), and biomass are gaining popularity due to their ease of use, low cost, and low environmental impact. The environmental issues, declining fuel supplies, and increasing energy demands have drawn our attention to the glimmer of hope for a future focused entirely on sustainable and non-polluting energy sources. Photovoltaic (PV) power generation is becoming more common in comparison to other renewable energy sources due to advantages such as ease of access, low cost, low environmental emissions, and lower maintenance costs. In this dissertation, three separate Maximum power point monitoring techniques are used to construct a solar PV system (MPPT). Modeling and simulation using the MATLAB Simulink programmeare being used to check the effectiveness of the proposed scheme. The model is investigated using two partial shading patterns. By providing different values of input radiations to all four modules connected in sequence, we were able to create partial shading conditions using the PV array block. The panel's output is fed to the optimization technique block, which then feeds the boost converter from their duty cycle output. Under partial shading, the results show that the Particle Swarm Optimization algorithm outperforms the Perturb and Observe and Incremental Conductance algorithms..
\end{abstract}

Keywords:-Photovoltaic (PV), Matrix laboratory (MATLAB)), Artificial Neural Network (ANN), Mega Watt Peak (MWp), Soft Computing Techniques, Maximum Power Point Tracker (MPPT).

\section{I.INTRODUCTION}

Solar cell is a photovoltaic principle-based electronic device that directly converts light energy into energy. It depends directly on how much light strikes the cells, the more light on the cell and the more powerIt makes it. To maximise the power supply from installed solar panelsSpacecraft are so designed that the panels face the sun constantlyRest of the body of the spacecraft may move and face a different direction.As we are all aware, energy from the sun (not a limited source) is renewable and isElectricity source totally unpolluted. Fossil fuels have been excavated, not burned.solar panels are a finite source of energy from the ground of large power plantsDirectly convert sunlight to power without harmful emissions. Solar cell directly converts light energy to direct electricity (DC).[2][4] 


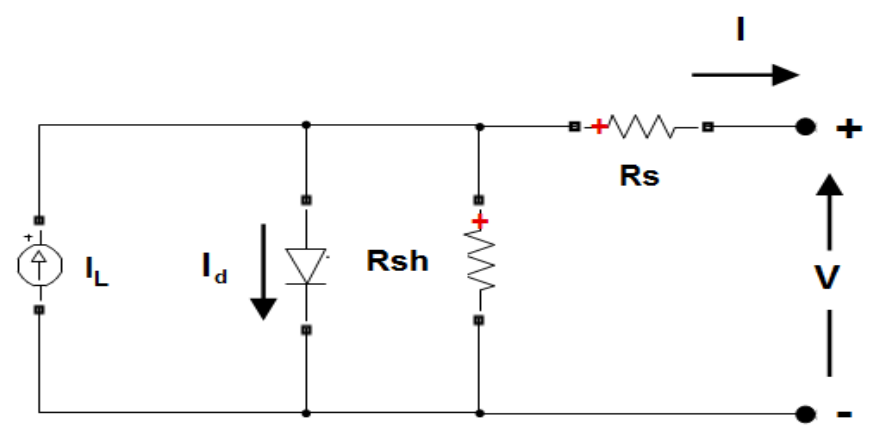

Fig. 1.1: Diode Modelling of Solar Cell

Solar cells do not use light-emitted heat energy to generate electrical energy.The photovoltaic effect of 1839 and the first thin film solar of 1883 were discovered. Solar cell production and the development of the first practical photovoltaic cell was done in 1954.Solar cell efficiency relies on many factors, such as cell shading, radiation, temperatur etc.Multiple junction cell achieved highest efficiency of $44.7 \%$ in 2014.

Solar cell is the basic unit of one or more layers of solar panelsWafers like silicone in semiconductors. When light photons strike these cellsDue to the "photovoltaic effect," they lead to power generation in the sunlight.Electric currents fluctuate between cells[3].

Figure 1.1 discusses the solar cell modelling diode. The solar cell diode model is used to measure the I-V and P-V characteristics of solar cells. The regulating equations for the diode model are discussed in light of the Rs and Rp effects.

$I=I_{S C}-I_{01}\left[e^{q\left(\frac{V+I . R_{S}}{k T}\right)}-1\right]-I_{02}\left[e^{q\left(\frac{V+I . R_{S}}{k T}\right)}-1\right]-\left(\frac{V+I R_{S}}{R_{p}}\right)$

$I=I_{S C}-I_{0}\left[e^{q\left(\frac{V+I \cdot R_{S}}{n k T}\right)}-1\right]-\left(\frac{V+I R_{S}}{R_{p}}\right)$

(1.2)Single PV cell generates usually less

than $2 \mathrm{~W}$ with about $0.5 \mathrm{~V} \mathrm{DC}$. So, to get therePower and voltage level desired, number of PV cells have to be connectedin a parallel-series setup.Tens of these PV cells, called solar modules, are packed togetherPacked into a single unit for the formation of solar panels on the roof once more,Arranged for maximising their direct sunlight exposure hours. Electrical powerThe direct current (DC) generated by all of these solar cells is whyCurrent is then sent to an inverter which makes it the alternative equivalent(AC). The obtained $\mathrm{AC}$ is then ready for home use or even for local use by appliancesNetwork for the distribution of electricity.Solar cells form a "module" which supplies current and voltage (and therefore power). For example, in a framework to frame a 12-volt module, 24 solar cells must be connected. A solar cell series is also known as a photovoltaic module. Current voltage opportunities are correlated with power. The power rating of a PV module is often quoted as the power output of the Module when sunlight occurs at 1000 watts/meter2 and the temperature is $25^{\circ} \mathrm{C}$. This is a middle of the unmistakable summer day with average sunlight. Therefore, a 1 square module with an efficiency of $15 \%$ would achieve a return of 150 Watts early afternoon. A photovoltaic (PV) exhibit contains a range of photovoltaic modules designed to generate power. A PV display can consist of a single module and, depending on the number and output, its output can move from a few watts to a large amount of megaWatts. A photovoltaic display generates the direct current From battery charging to a suitable device powering a structure or town in a mini-computer. When a PV cluster is connected to the utilities network, an inverter should be initially connected, which will change the current immediate current. The efficiency of most inverters is around 90 percent. The new inversion systems are advanced and produce extremely clean, constantly voltage electricity. [12]By clean power one means that the spinning current is like a sine wave almost without mutilation or harmonics. The aim is to improve solar photovoltaic system operational efficiency through 
maximum power point surveillance. The source impedance and the load impedance can be adapted by the adjustment of the corresponding boost cycle and a complete power transfer monitoring can be achieved from the photovoltaic system.

\section{MAXIMUM POWER POINT TRACKING}

A maximum operating point is obtained at every Power-Voltage or Curve of a solar panel, where the solar panel provides the maximum power to the load. This separate point is referred to as a solar panel's maximum power point (MPP).The solar panels are photovoltaic in nature (Power-Voltage or currentvoltage)Temperature and irradiance (radiant energy flows per) depend on curvesLevels of unit area.In other words, the sun depends on the size of the panels per areaThe curve varies therefore the maximum point or the MPP varies accordingly. The current and voltage that maximise can therefore be deduced.With environmental conditions, power output will change.

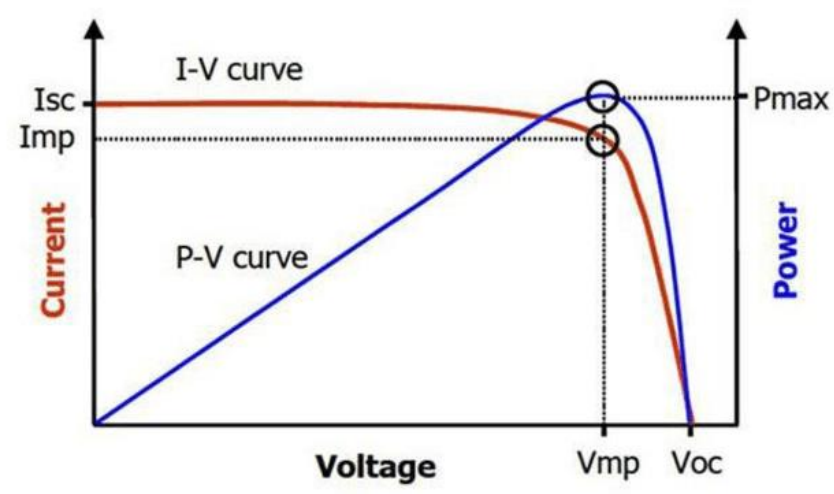

Fig. 1.2: Maximum Power Point of Solar Cell

Figure 1.2 shows that the MPP depends on some conditions like theThe level of irradiance is here referred to by the symbol "G," for example. In other waysG values, the corresponding shift can be seen from the graphMPP's values.A MPPT algorithm must therefore be used to continuously track the MPP.The maximum power instance leads to higher system efficiency. InThe demand for load can be higher than that provided by the PV for various applicationsSystem. There are therefore many different approaches that range from simple to simpleParameter relationships to time-based analysis to maximisePV systems power generation.

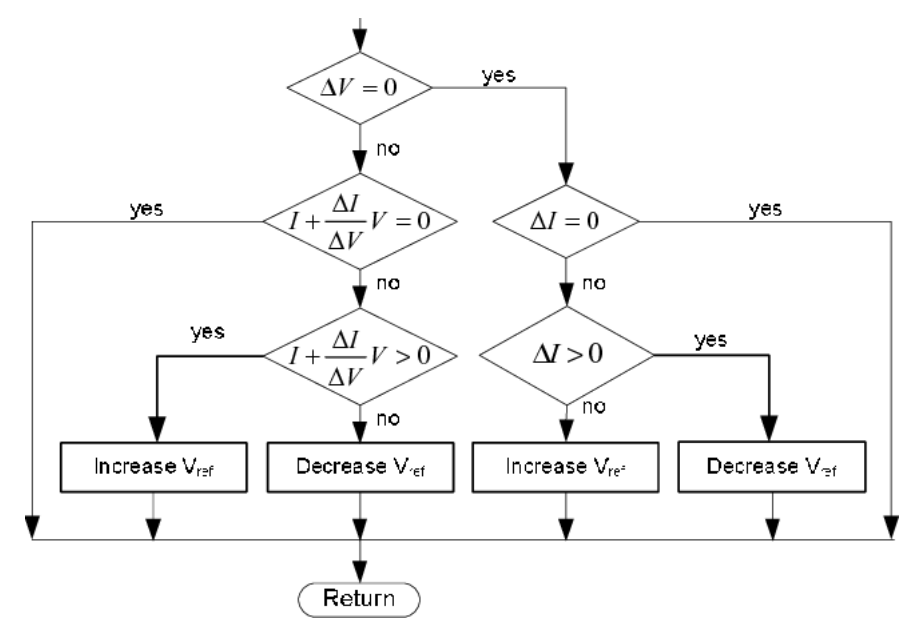

Fig. 1.3: Incremental Conductance MPPT Method 
In determining solar cell efficiency, temperature also plays an important role. By theincrease of temperature, increases the rate of photon generation, leading to band gap reduced because of the reverse saturation current is increasing. This process therefore leads to aMarginal current change but considerable voltage difference. With each of themThe cell voltage reduces by a step $2.2 \mathrm{~V}[5]$ the temperature rise degree.Thus, solar cell performance and temperature share a negative relation. In cold and bright sunny days, cells show their best performance rather than warm and hot.Sunny days luminous. Solar panels are currently produced with non-silicon materialsThose that are insensitive to temperature. They are thus used under or near the roomConditions of temperature. The incremental is based on the observation of the P-V curve. The method of INC was proposed to track maximm power. It is to overcome this algorithmThe $\mathrm{P} \& \mathrm{O}$ algorithm has some of the disadvantages. The highest power wastracked by the relationship between the current variation and the variationvoltage and the negative voltage power ration, i.e. $\mathrm{dI} / \mathrm{dV}$ and $-\mathrm{I} / \mathrm{V}$.The fundamental principle governing the progressive behaviour method is that The photovoltaic module P-V curve is zero at the highest point of power, positiveThe maximum point on the left and the negative on the right. This is possible by,Therefore, the maximum power point to the right of the point, i.e. $\mathrm{dI} / \mathrm{dV}<-\mathrm{I} / \mathrm{VTo}$ reach the MPP, the PV panel operating voltage must then be decreased.The method of incremental conductivity gives greater efficiency than the method of P\&O.It reduces power loss by significantly reducing oscillations and thus the systemcost has been lowered.

\section{PARTICLE SWARM OPTIMIZATION}

PSO provides a search program based on population, in which individuals are called partial changes, their position in time. In the PSO system, the particles fly in a multidimensional search space. Each particle adjusts its position according to it during the flight. Own experience and experience Adjacent particles, using the best position It is found by itself and its neighbors. Optimum in the multidimensional space that seeks a solution to move each particle of the group. Get the best point by adding the speed position. The velocity of the particle is affected by three components, namely inertia, cognitive and society. The inertial component simulates the inertial behavior of birds that fly in the previous direction. The cognitive components mimic the memory of the birds on their best location and the social component simulates the birds' memory, the best location in some of the trees. Movement of particles around the multidimensional search space until they find the best solution. The speed of modification of each one can use the current speed and the calculation agent. The distance to Pbest and Gbest is as follows.[15]

$$
\mathrm{V}_{\mathrm{i}}^{\mathrm{k}+1}=\mathrm{W} \times \mathrm{V}_{\mathrm{i}}^{\mathrm{k}}+\mathrm{C}_{1} \times \mathrm{r}_{1} \times\left(\text { Pbest }_{\mathrm{i}}^{\mathrm{k}}-\mathrm{X}_{\mathrm{i}}^{\mathrm{k}}\right)+\mathrm{C}_{2} \times \mathrm{r}_{2} \times\left(\text { Gbest }^{\mathrm{k}}-\mathrm{X}_{\mathrm{i}}^{\mathrm{k}}\right)
$$

Where, $V_{i}^{k}$ The speed of individual $i$ when iterating $k, X_{i}^{k} \quad$ Individual $i$ is in the position of iteration $\mathrm{k}, \mathrm{W}$ inertial weight $\mathrm{C} 1, \mathrm{C} 2$ acceleration factor, $\mathrm{Pbest}_{\mathrm{i}}^{\mathrm{k}}$ The best position of individual $\mathrm{i}$ in iteration $\mathrm{k}$, Gbest ${ }^{\mathrm{k}}$ Group's best position until iteration $\mathrm{k} \mathrm{r} 1$, $\mathrm{r} 2$ Random number between 0 and 1 . Accelerate during this speed update the coefficients $\mathrm{C} 1, \mathrm{C} 2$ and the inertia weight $\mathrm{W}$ are Predefined and $\mathrm{r} 1, \mathrm{r} 2$ are randomly generated uniformly The number is in the range $[0,1]$. In general, inertia the weight $\mathrm{W}$ is set according to the following equation: 


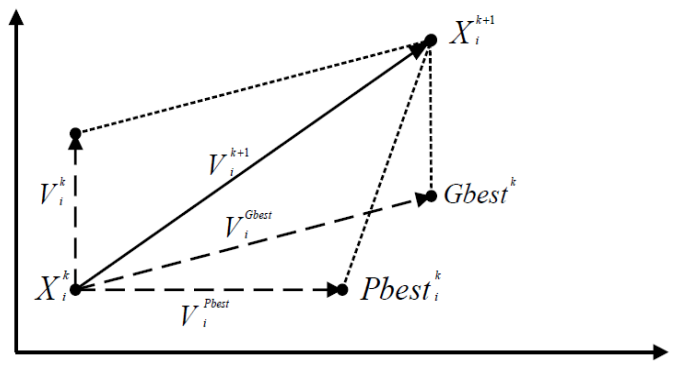

Fig 1.4 Search mechanism of PSO

The modified velocity equation (6) is given by:

Where $\varphi=C_{1}+C_{2}, \varphi>4$

$$
\begin{gathered}
V_{i}^{K+1}=K \cdot\left(W \cdot V_{i}^{k}+C_{1} G_{d}()\left(\text { Pbest }_{i}^{k}-X_{i}^{k}\right)+C_{2} C_{d}()\left(\text { Gbest }^{k}-X_{i}^{k}\right)\right) \\
K=\frac{2}{\left|2-\varphi-\sqrt{\varphi^{2}-4 \varphi}\right|}
\end{gathered}
$$

The convergence characteristic of the system can be controlled by. The contraction factor (CFA) be method must be greater than 4.0 to guarantee stability. But as the $\varphi$ Increase of the $\mathrm{K}$ factor is reduced, diversification is reduced, it produces a slower reaction. Usually, when contraction factors are used, $\varphi$ is set to 4.1 (ie, C1, C2 $=$ Therefore, the constant multiplier $\mathrm{K}$ is 0.729.QPSO, proposed and developed by Sun et al., Is the expansion of the PSO in the field of quantum computing The concept of qubits and revolving doors are here to present the improvement of demographic characteristics Diversity Qubit and angle Represents the state of the particle instead of the position and velocity of the particle completed in the Basic PSO Therefore, QPSO has powerful search capabilities and powerful search capabilities. Convergencefeature. The basic difference between a qubit bit and a classical bit is that the latter can remain at the same time Superposition of two different quantum states,

$$
|\psi\rangle=\alpha|0\rangle+\beta|1\rangle
$$

In the above equation, $\alpha$ and $\beta$ are complex numbers that satisfy the equation

$$
|\alpha|^{2}+|\beta|^{2}=1
$$

The rotation state is represented by $|0\rangle$ and the rotation state is It is represented by $\mid 1>$. As can be seen from (1), a qubit is Represents two information states (|0> and $\mid 1>$ ) simultaneously. This superposition state can also expressed as

$$
|\psi\rangle=\sin \theta|0\rangle+\cos \theta|1\rangle
$$

Where the phase of the qubit is represented by $\theta$. the relation among $\alpha, \beta$ and $\theta$. The relation among $\alpha, \beta$ and $\theta$ can be defined as the position of the particle in QPSO.[13]

\section{PROPOSED METHODOLOGY}

PSO technique is carried out in two step namely Particle initialization and function evaluation. In first step the particle is initialized and the parameters are controlled which is very important because this step in a way controls the exploration and exploitation and hence improves the result.In Particle Swarm Optimization technique, a term called velocity clamping is utilized which basically helps the particle to stay within the boundary and take reasonable step sizes so as to comb throughout the searching space. The importane of velocity clamping lies in the fact that without this, the process could explode and the position of particle change rapidly. Maximumvelocity controls the granularity of the searching area by creating a quick balance between local and global exploration. Hence we can say that 
velocity clamping varies the step size of the particle and its searching direction.If the swarm size is big, then we have to cover larger parts of the search space in every iteration which in turn increases the complexity and time involved.Comparing to other optimization techniques, PSO method somewhat has lower sampling time,ability to swiftly converge towards an optimum solution, doesnot require gradient information of the function, simple mathematical analysis using primitive operators, easy to implement, economical to use provides faster tracking under changing environmental parameters, faster and has higher efficiency. It gives updated convergence velocity steadily. In addition to this, it provides us with the utmost efficiency utilization with no requirement of initial parameter calculation, dreivative free algorithm, limited number of parameters, less dependent on initial points.Since we require an efficient and accurate solar system, hence we need to consider weather conditions. The two main environment factors which affect the system performance are temperature and solar radiations. In order to avoid the PV mismatch problem, we have drawn the characteristics curve in both conditions i.e. normal and partial shading. From the curves, we found that during partial shading on cloudy day, multiple peaks occur while in normal condition we obtain only one peak.

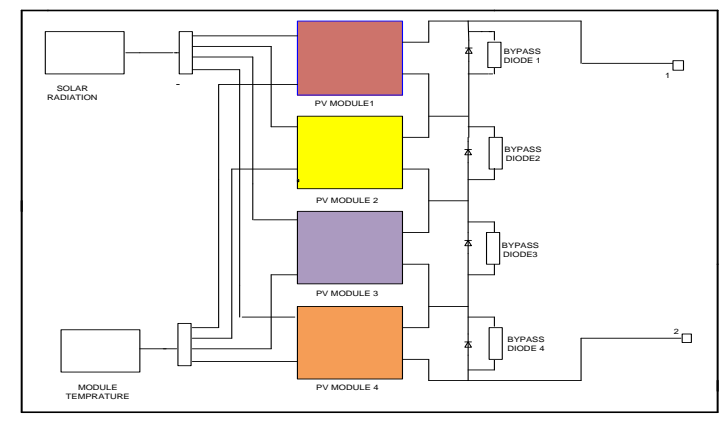

Fig. 1.5: Simulation of Solar PV System Operational Condition

The multiple peaks obtained during partial shading can be better called as local peak and among them we have to find the highest one which is the global power peak and hence this way the challenge to find the maximum value of power point is aggravated further.During shading conditions, various problems are need to be taken into account like cost, algorithm, complexity of the system and hence proper connection need to be made so that the system works properly under varying atmospheric conditions..Particle swarm optimization is the most sought after technique when it comes to the case of partial shading owing to its effectiveness and higher tracking speed. It manages the optimal voltage in the best way which makes it easier to locate the maximum power point. In this approach, various parameters are pre decided before starting. After that, we need to choose a vector voltage ( V1 to Vd, where ' $d$ ' is module) which is managed with the system in order to track the maximum power point. Here we compare output voltage with the actual voltage. The coding for this algorithm is written in the MATLAB software.

From the flowchart, we found a function ' $F$ ' whichdoesnot remain constant and changes with the weather and hence the condition function is re-initialized again and again to get the new maximum power point.

The PV system comprises of a PV array connected to a DC/DC boost converter whose duty cycle is managed by the PSO optimization technique. In our system, we have divided two PV modules into four groups which further contains 18 cells connected in series with the bypass diode. Among the four groups, some receive partial shading while some are getting half and full. The voltage obtained from the PV array is passed through the converter which consist of a MOSFET switch, inductor, capacitors and load resistance. 


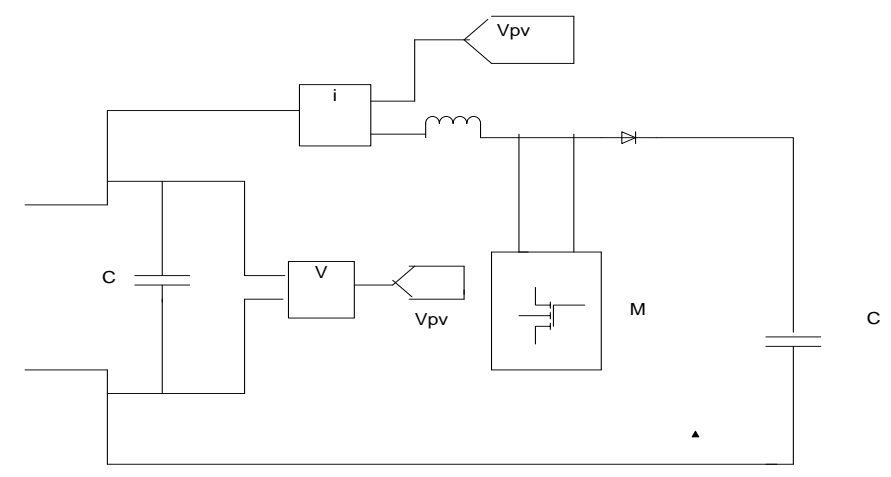

Fig. 1.6: Design of Duty Cycle Control System

\section{V.RESULTS}

In this research a soft Computer Baed charge Controller was designed to efficiently monitor the maximum IV power points of PV systems with complex working conditions and has managed soft computer-based control systems with enhanced incemental conductance based trained artificial neural network configuration and duty cycles.

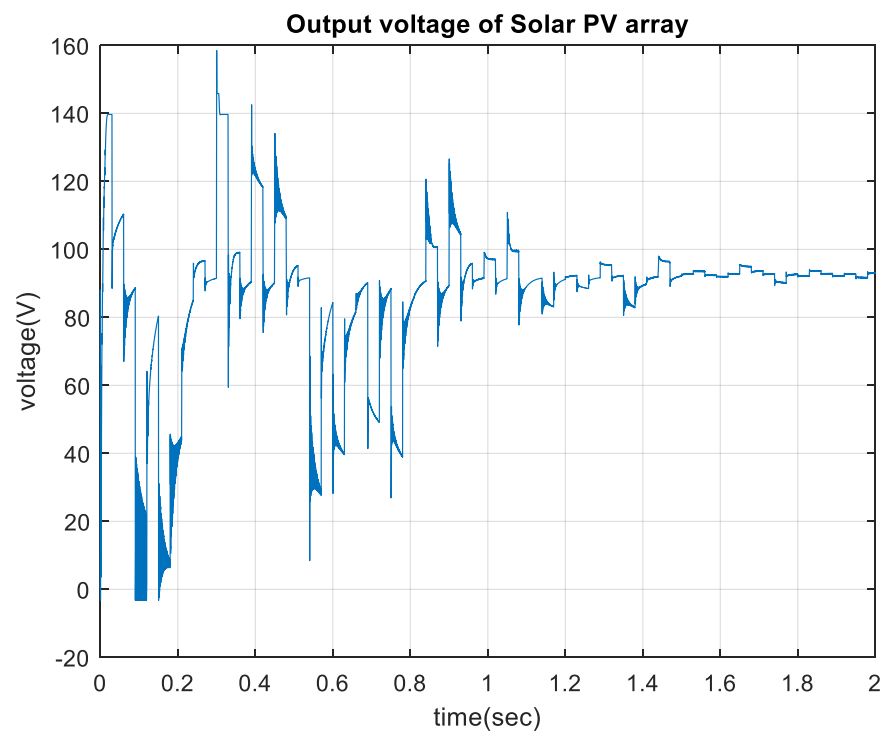

Fig. 1.7 Voltage waveform of Solar PV System

Results have been explained with the figure of merits. The graph and plots explains the performance of the simulated system. Figure 1.8 represents the current whereas 1.9 represents the voltage of the solar PV system. The voltage and current matrix is given to deduce the characteristics and it serve the objective function to maximize the power with selection of optimum duty cycle. Figure of merit has been shown in figure 1.11 and figure 1.12 in which the tracked power has been shown and compared with the conventional algorithms. 


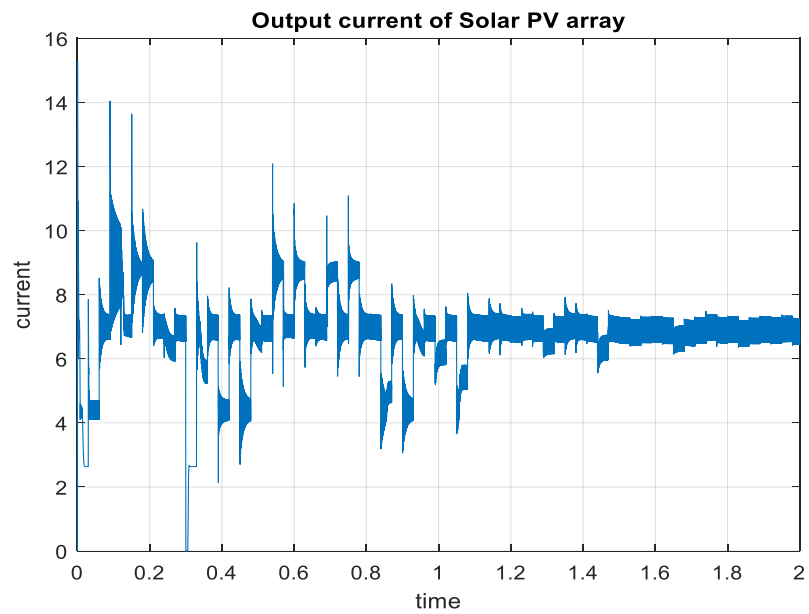

Fig. 1.8Output current waveform of Solar PV array

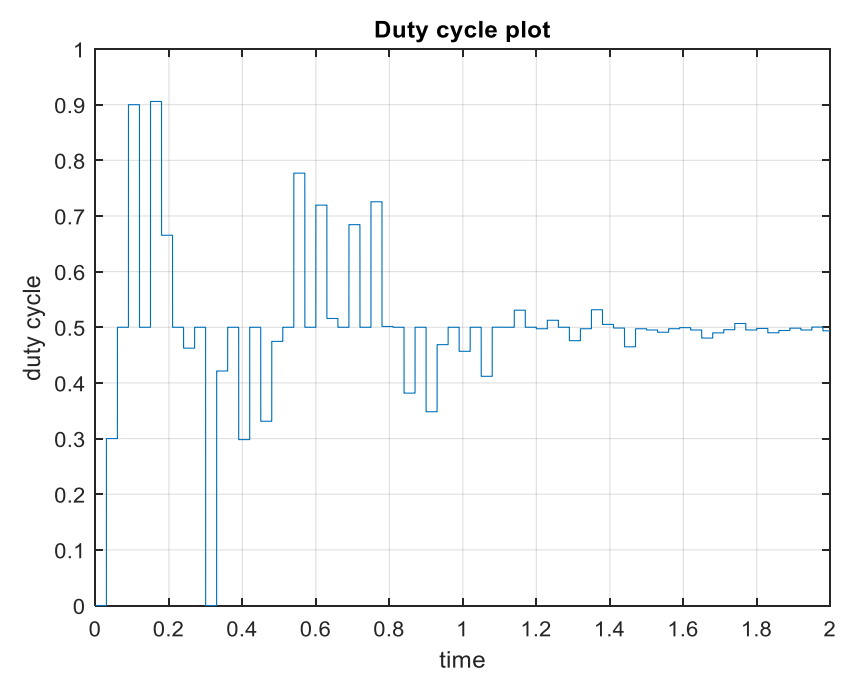

Fig. 1.8 Duty cycle plot for System

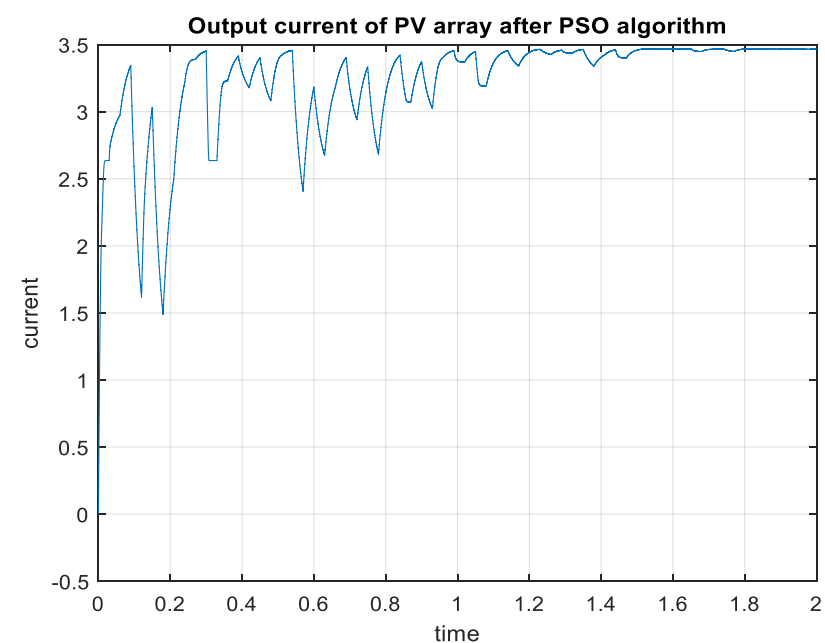

Fig. 1.9 Output current waveform of Solar PV after Optimization Using PSO 


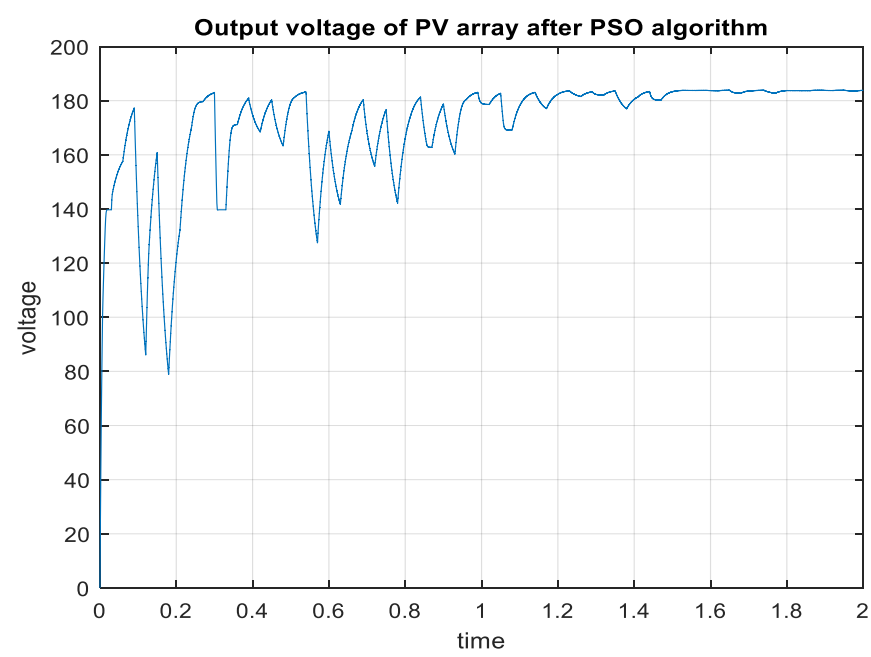

Fig. 1.10 Output voltage waveform of PV array after applying PSO algorithm

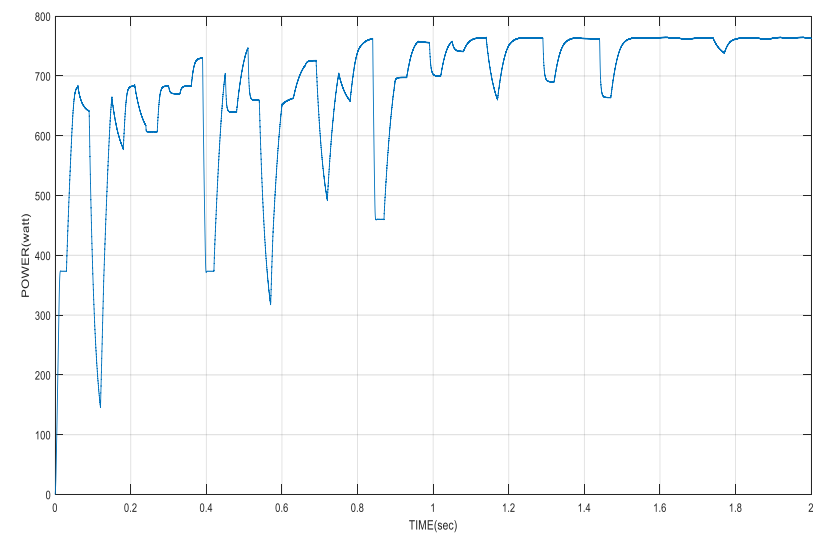

Fig. 1.110utput power waveform of PV array after applying PSO algorithm

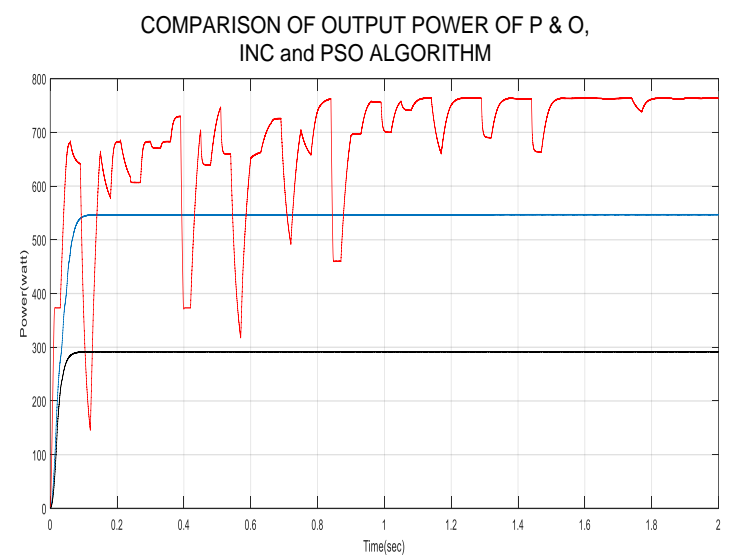

Fig. 1.12 Comparison of Output power with Conventional Algorithms 
Table-1 Comparative Evaluation (Peak-785 Watt)

\begin{tabular}{|l|l|l|l|}
\hline Name of Method & Peak Power & Time of Reaction & Time of Stability \\
\hline P and O & 291 watts & 0.0011 seconds & 0.179 seconds \\
\hline INC & 522watts & 0.0011 seconds & 0.179 seconds \\
\hline PSO & 785 watts & 0.0011 seconds & 1.59 seconds \\
\hline
\end{tabular}

Table1 represents the implementation of different algorithms under partial shading condition and it can be clearly perceived that the PSO algorithm tracks the maximum power after some transient response which occur during the first 0.001 seconds. Also, there are many iterations before it attains the steady state response. We can clearly see that the algorithm starts tracking from the initial 0.0 second and achieve steady state in 0.001 seconds while other algorithms take longer time. Also, PSO is able to track more power than other algorithms. Hence it can be said that PSO algorithm performs better under variable temperature and radiation conditions. The introduction of an efficient charge controller based on an intelligent maximum energy monitoring system increases solar photovoltaic system operating efficiency. With Solar Photovoltaic system storage applications and high power inversors, a batterycontaminated charging controller can be interacted.

\section{VI.CONCLUSION}

During this research, improved PSO based power point controller has been designed to monitor efficiently with variable irradiance and complex operating conditions. The maximum power point was extracted from I V characteristics of photovoltaic systems, and has managed the soft computer program based controls with boost configuration and operating cycles based on enhanced PSO methodology. The controller is connected to the PV modules and the battery on the storage system and on the inverter. In accordance with current research aspects, an improvement is made in the operating efficiency of the photovoltaic solar system through the use of an efficient power converter equipped of a soft-computer MPPT controller. The introduction of an efficient charge controller based on an intelligent maximum energy monitoring system increases solar photovoltaic system operating efficiency. The research can be extended to include inclusion of deep learning convolutional neural network for design and analysis of photovoltaic system.

\section{REFERENCES}

[1] Sriram, M., \& Ravindra, K. (2020). Backtracking Search Optimization Algorithm Based MPPT Technique for Solar PV System. In Advances in Decision Sciences, Image Processing, Security and Computer Vision (pp. 498-506). Springer, Cham.

[2] Satapathy, Susree Sukanya, and Nishant Kumar. "Wavelet Mutation based JAYA Optimization Algorithm for Global Maximum Power Peak Searching for Partially Shaded Solar PV Panel Condition." In 2019 3rd International Conference on Recent Developments in Control, Automation \& Power Engineering (RDCAPE), pp. 351-356. IEEE, 2019.

[3] S Saravanan, N. Ramesh Babu, Performance Analysis of Boost \&Cuk Converter in MPPTBased PV System, 2015, IEEE International Conference on Circuit, Power and ComputingTechnologies [ICCPCT], 978-1-4799-7075-9

[4] Z. Cheng, H. Zhou, and H. Yang, "Research on MPPT control of PV system based on PSO algorithm," 2010 Chinese Control Decis. Conf. CCDC 2010, pp. 887-892, 2010. 
[5] Li, Shuhui, and Huiying Zheng. "Energy extraction characteristic study of solar photovoltaic cells and modules." In Power and Energy Society General Meeting, 2011 IEEE, pp. 1-7. IEEE, 2011.

[6] Sharma, Rahul S., and P. K. Katti. "Perturb \& observation MPPT algorithm for solar photovoltaic system." In 2017 International Conference on Circuit, Power and Computing Technologies (ICCPCT), pp. 1-6. IEEE, 2017.

[7] C.-L. Liu, Y.-F. Luo, J.-W. Huang, and Y.-H. Liu, "A PSO-based MPPT algorithm for photovoltaic systems subject to inhomogeneous insolation," 6th Int. Conf. Soft Comput. Intell. Syst. 13th Int. Symp. Adv. Intell. Syst., no. 1, pp. 721-726, 2012

[8] Pillai, Hodgson, Insaurralde, Pinitjitsamut and Deepa, "The techno-economic feasibility of providing solar photovoltaic backup power," 2016 IEEE International Symposium on Technology and Society (ISTAS), Kollam, 2016, pp. 1-6.

[9] A real maximum power point tracking method for mismatching compensation in PV array under partially shaded conditions," IEEE Trans. Power Electron., vol. 26, no. 4, pp. 1001-1009, 2011.

[10] Q. Duan, J. Leng, P. Duan, B. Hu, and M. Mao, "An Improved Variable Step PO and Global Scanning MPPT Method for PV Systems under Partial Shading Condition," in 7th International Conference on Intelligent Human-Machine Systems and Cybernetics, pp. 382$386,2015$.

[11] P. Lei, Y. Li, and J. E. Seem, "Sequential ESC-based global MPPT control for photovoltaic array with variable shading" ,IEEE Transactions on Sustainable Energy, vol. 2, no. 3, pp. 348358, 2011.

[12] B. N. Alajmi, K. H. Ahmed, S. J. Finney, B. W. Williams, and B.Wayne Williams, “A Maximum Power Point Tracking Technique for Partially Shaded Photovoltaic Systems in Micro grids" ,IEEE Transactions on Industrial Electronics, vol. 60, no. 4, pp. 1596-1606,2011.

[13] K. Chen, S. Tian, Y. Cheng, and L. Bai, "An Improved MPPT Controller for Photovoltaic System Under Partial Shading Condition,” Sustain. Energy, IEEE Trans., vol. 5, no. 3, pp. 978 985, 2014.

[14] J. Ahmed, S. Member, and Z. Salam, "An Improved Method toPredict the Position of Maximum Power Point During Partial Shadingfor PV Arrays,” IEEE Trans. Ind. Informatics, vol. 11, no. 6, pp.1378-1387, 2015.

[15] Hariharan, M. Chakkarapani, G. S. Ilango, C. Nagamani, and S.Member, "A Method to Detect Photovoltaic Array Faults and Partial

Shading in PV Systems," IEEE J. Photovoltaics, pp. 1-8, 2016.

[16]Uzunoglu, M., and M. S. Alam. "Dynamic modeling, design, and simulation of a combined PEM fuel cell and ultracapacitor system for stand-alone residential applications." IEEE Transactions on Energy Conversion 21.3 (2006): 767-775.

[17]Onar, O. C., M. Uzunoglu, and M. S. Alam. "Modeling, control and simulation of an autonomous wind turbine/photovoltaic/fuel cell/ultra-capacitor hybrid power system." Journal of Power Sources 185.2 (2008): 1273-1283.

[18]Hidaka, Yasuhito, and Koji Kawahara. "Modeling of a hybrid system of photovoltaic and fuel cell for operational strategy in residential use." Universities Power Engineering Conference (UPEC), 2012 47th International. IEEE, 2012.

[19]Gaonkar, D. N., and Sanjeev Nayak. "Modeling and performance analysis of microturbine based Distributed Generation system, “a review”." Energytech, 2011 IEEE. IEEE, 2011.

[20]Khan, M. J., and M. T. Iqbal. "Pre-feasibility study of stand-alone hybrid energy systems for applications in Newfoundland." Renewable energy 30.6 (2005): 835-854. 